\title{
Understanding Relationship between Milestone and Decision-Making in Project Management: A Qualitative Study among Project Managers in Saudi Arabia
}

\author{
Umar Altahtooh $^{1} \&$ Thamir Alaskar ${ }^{2}$ \\ ${ }^{1}$ Taibah University, Madinah, Saudi Arabia \\ 2 Al-Imam Muhammad Ibn Saud Islamic University, Riyadh, Saudi Arabia \\ Correspondence: Umar Altahtooh, Taibah University, Madinah, Saudi Arabia. E-mail: utahtooh@taibahu.edu.sa
}

Received: February 23, 2018

Accepted: June 10, 2018

Online Published: June 30, 2018

doi:10.5539/ijbm.v13n8p184

URL: https://doi.org/10.5539/ijbm.v13n8p184

\begin{abstract}
Despite the importance of milestone as a key knowledge in project management, there has been lack of research to understand the relationship between milestones and decision-making. This paper presents a pragmatic research context that aims understanding the nature of milestones and their relationship with different decision-making structures and responsibilities across projects. Data were collected through 14 semi-structured interviews with project managers and analyzed using thematic analysis. The findings explore the concepts of project milestones among project managers in Saudi Arabia. The paper finds that there is a relationship between milestones and the impact on decision-making.
\end{abstract}

Keywords: decision-making, milestone, project management, Saudi Arabia

\section{Introduction}

Every project has start and finish dates for specific activities and ability to meet these dates on time schedule is one important element to achieve a successful project. A milestone is a main knowledge in project management methodology. This paper is qualitative and descriptive in its approach. The purpose of the study is to answer the following research questions:

- What is the importance of milestones in project management?

- Is there a relationship between milestones and decision-making through project life cycle?

According to Ferreira and Tereso (2014), milestones are useful to track the progress of project over time. To study the importance of milestones in project management and to answer the above questions, semi-structured interviews were used to collect data in the context of a pragmatic approach. Then, thematic analysis was used to analyze each qualitative interview data and to identify themes within the responses.

The next section of this study gives an outline of milestones and decision-making in project management. Then, section 2 describes the research method. Section 3 discusses the results. Finally, section 4 summaries the findings.

\section{Literature Review}

It is important to note that the concept of project schedule becomes a serious subject when managing, executing and monitoring various projects. However, a milestone is a significant tool in project management schedule.

\subsection{Project Management Schedule}

Today, most contemporary projects have schedules that include project time planning. Halloran (2010) thinks that a project schedule is "a road map" for tasks and duration estimates that give a right direction for the project. According to Magalhães-Mendes (2011), the project schedule is "the core of the project plan". However, developing project schedules are maybe the most challenging activity in project management environment (Art Gowan et al, 2006). Furthermore, it is a main root of conflict between the project team and senior management (Barczak and Wilemon, 2001). Tam (1998) defines a project schedule as a plan of action contained within a timeline. Douglas (2004) thinks that it is a tool used to measure progress towards the intended results of a project. Moreover, Wigal (1990) shows that it is required to see the progress of a project and also to overcome delay. 
Preparing project schedule requires estimation of project activities' durations (Ahtee, 2007). In terms of structure, a work breakdown structure (WBS) is a key element in a data structure of a project schedule (Vanhoucke, 2011). Nevertheless, Basu (2003) shows that missing scope and incomplete WBS analysis cause the biggest influence on a project schedule. According to Chen et al (2015), an effective project schedule leads to:

- Increase their efficiency of project execution;

- Maximize profit;

- Minimize wastage of resources.

Holding effective project status meetings is one way to manage a project schedule (Schifalacqua et al., 2009). Gutfeld et al. (2014) think that an iterative process leads to the improvement project schedule. According to Malladi et al. (2011), a project schedule links with the following elements:

1. Deliverables,

2. Timelines,

3. Review and feedback mechanisms,

4. Plans for project,

5. Risk,

6. Communication

7. And quality management.

Milestones are main part of a project schedule (Soja et al., 2011). Hormozi and Dube (1999) think that using milestone reporting is a way to make controlling a project schedule. Tausworthe (1980) mentions that "If a project has identified a certain number of equal effort "unit" milestones to be achieved during the course of implementation, then the mere number of such milestones achieved by a certain date is an indicator of the progress toward that goal" (p. 181). Project milestone is a goal that should be met by project team. Projects will not often finish on time if milestones are delayed. According to Klimek and Lebkowski (2013), a milestone is "a set of activities with the same deadline" (p 1008). Wallin et al. (2002) define a milestone as "a scheduled event that marks the completion of one or more important tasks and it is used to measure achievements and development progress" (p. 4).

In context of project management software, a milestone is the end of a project stage (Bergner and Friedrich, 2010). In terms of location, Laporte et al (2012) show that a milestone is located at the ends of phases. According to Rosenfelt (2000), milestones have no duration but act as checkpoints in the project work. Furthermore, Colenso (2000) shows that a milestone is known as an activity of zero duration. Thus, a milestone is "a significant point or event in the project" (PMI, 2008, p 136). According to Kampe (2012), the characteristics of good milestones include the following elements:

- $\quad$ Specific

- Measurable

- Achievable

- Relevant

- Timely

A project schedule hierarchy consists of five levels that can be used for large projects as shown in Figure 1 (Hietala, 2009).

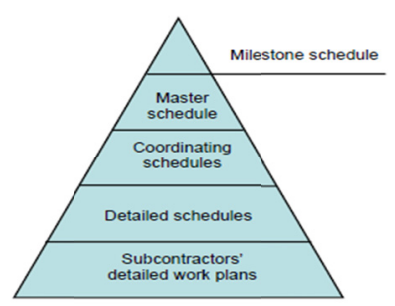

Figure 1. Schedule hierarchy 


\subsection{Decision-Making}

Decision-making is a significant practice which is integral in everything people do (Saaty, 2004). Although decision-making is an important skill of management, many project managers lack decision-making skills. Hwang (2012) defines decision-making as the process of choosing a potential course of action from all the available options. In terms of organization, decision making is difficult to manage (Helge Becker, 2003). Organizational decision-making is depend on two main concepts: strategy and cognition (Vermeulen, 2010). Marshall (2014) thinks that organizational decision-making is influenced by the following elements:

- Political

- Ideological and pragmatic factors

- Personal experience

In terms of style, Doktor and Hamilton (1973) believe that decision-making is a cognitive style. Harren (1979) categorizes decision-making styles into:
1. Planning
2. Intuitive
3. Dependent

Furthermore, Scott and Bruce (1995) develop the decision-making typology that consists of five styles:

1. Rational

2. Intuitive

3. Spontaneous

4. Dependent

5. Avoidant

However, according to Thirumalai and Senthilkumar (2017), the decision making in competitive environment is more sophisticated; in addition, within the complex competitive environment, making logical decision is effected by certain circumstances. There are two types of decision-making: centralized and decentralized. Centralized decision-making is costly, slow and delayed actions in terms of bureaucracy (Vagstad, 2000; Sobel \& Leeson, 2006). However, it is positively related with the frequency of administrative changes (Huber et al, 1993). Baker and Abou-Ismail (1993) show that centralized decision-making is the general practice of Saudi managers. On the other hand, decentralized decision-making is more effective in uncertain situations (Petrick, \& Susman, 1997). Moch \& Morse (1977) show that decentralized decision making is positively related with making an innovative organizational environment. However, decentralized makes collecting data difficult (Kingsbury, 1994). In terms of risk, Schwarcz (2015) thinks that decentralized decision-making is more likely to protect managers from liability. Figure 2 shows the steps of decision-making according to Hitt et al. (2006): Define the problem

- Identify criteria

- Gather and evaluate data

- List and evaluate alternatives

- Select best alternative

- Implement and follow up 


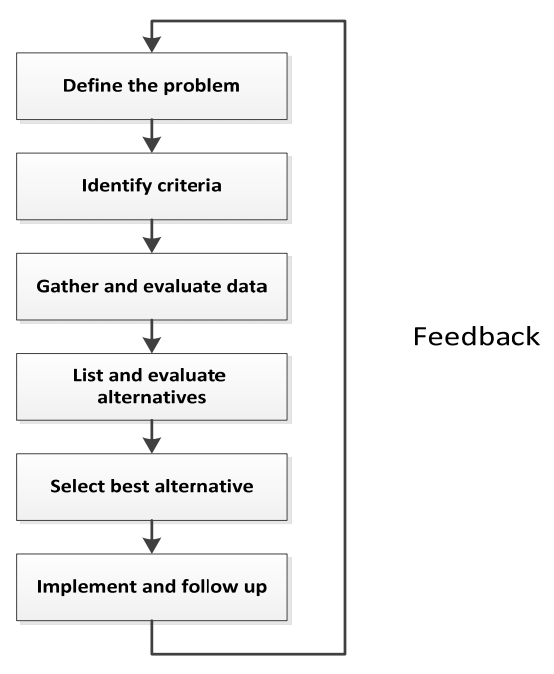

Figure 2. Steps of Decision-making

Source: Hitt et al., 2006.

\section{Method}

The aim of this paper is to realize and explore the relationship between milestones and decision-making in the project life cycle by interviewing project managers to gather rich qualitative data. The qualitative method provides subjective perspective of experiences and visions to obtain the best information that have not been studied in Saudi Arabia before. Daymon and Holloway (2002) show that when the interviewees state their beliefs and opinions, they can give information from the past to present. The interviews were conducted with 14 project managers in 7 industrial companies in Saudi Arabia. In this study, data were collected through semi-structured interviews. To test the reliability of the interview questions of the study, a pilot study was done to determine the required changes and to improve the questions. None of questions in the interviews obtained the disclosure of confidential information.

Between 9th August and 4th October 2016, the project managers were interviewed for 50 minutes. Each interviewee was asked the same questions to increase the reliability of the data. The interviews were performed in their offices. With the prior consent of the participant, the semi-structured interviews were recorded and transcribed. However, two of the interviews were not transcribed entirely because of poor recording quality. All unrelated discussions were excluded from the analysis. The Arabic interviews were partly transcribed and translated into English.

Thematic analysis is employed to analyze the results of these interviews to classify the most frequent replies and to explore the relationship between milestones and decision-making as shown below.

\section{Results}

Data analysis is defined as "a range of techniques for sorting, organizing and indexing qualitative data" (Mason, 2002, p. 9). Although thematic analysis is a method that can be used with any form of qualitative study; however, it is often used in exploratory and discovery stage of research (Boyatzis, 1998). Braun and Clarke (2002, p. 79) defines thematic analysis as "'a method for identifying, analyzing and reporting patterns (themes) within the data". Miles and Huberman (1994) show the thematic analysis process that consists of three phases: 1) data reduction, 2) data display and 3) data conclusion as shown in below figure. The first phase (data reduction) is the process of selecting, coding and categorizing the data. Second, the data display is a technique of organizing and presenting information. Finally, the conclusions are drawn, summarized and verified based on the data display. 


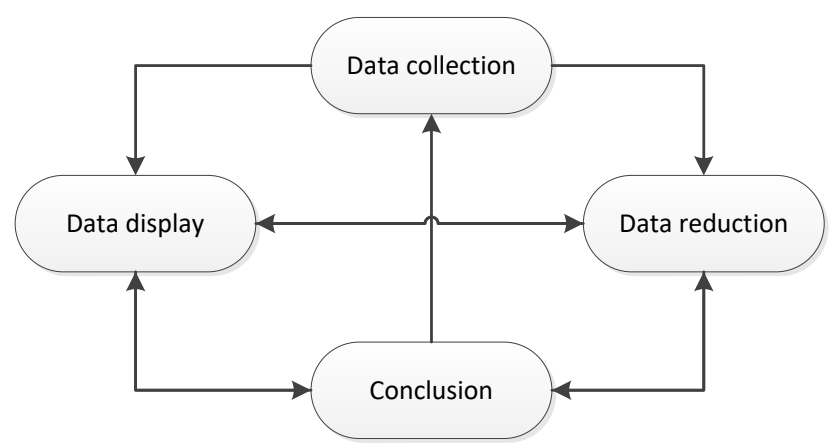

Figure 3. Data analysis process

Adapted from: Miles and Huberman, 1994.

\subsection{Information of Project Managers}

Table 1 shows that ten of project managers were in their forties while four were in their thirties. Regarding the level of education, thirteen of interviewees had completed a bachelor's degree, while only one had completed a master's degree. In terms of nationality, nine of participants were Saudi while five were non-Saudi. The sample of project managers was from seven industrial companies in Saudi Arabia. Regarding experience, four of project managers had more than 10 years' experience in the field of project management, nine had between 5 and 10 years' experience and one had less than 5 years' experience. Participants had been involved as a project manager between one and four.

Table 1. Information of project managers

\begin{tabular}{lllllll}
\hline $\begin{array}{l}\text { Project } \\
\text { Manager \# }\end{array}$ & Age & $\begin{array}{l}\text { Education } \\
\text { Level }\end{array}$ & Nationality & $\begin{array}{l}\text { Industrial } \\
\text { Company }\end{array}$ & $\begin{array}{l}\text { Number of Years' Experience } \\
\text { in the Field }\end{array}$ & $\begin{array}{l}\text { Number of Projects } \\
\text { as PM }\end{array}$ \\
\hline $\mathbf{0 1}$ & 45 & Bachelor & Saudi & Company 1 & 12 & 4 \\
$\mathbf{0 2}$ & 43 & Bachelor & Saudi & Company 1 & 10 & 3 \\
$\mathbf{0 3}$ & 40 & Bachelor & Saudi & Company 1 & 7 & 2 \\
$\mathbf{0 4}$ & 39 & Bachelor & Saudi & Company 2 & 6 & 2 \\
$\mathbf{0 5}$ & 41 & Bachelor & Non-Saudi & Company 3 & 7 & 2 \\
$\mathbf{0 6}$ & 40 & Bachelor & Saudi & Company 3 & 9 & 3 \\
$\mathbf{0 7}$ & 44 & Master & Non-Saudi & Company 4 & 15 & 5 \\
$\mathbf{0 8}$ & 33 & Bachelor & Saudi & Company 4 & 6 & 2 \\
$\mathbf{0 9}$ & 31 & Bachelor & Saudi & Company 5 & 4 & 1 \\
$\mathbf{1 0}$ & 42 & Bachelor & Saudi & Company 5 & 10 & 3 \\
$\mathbf{1 1}$ & 45 & Bachelor & Saudi & Company 5 & 13 & 2 \\
$\mathbf{1 2}$ & 36 & Bachelor & Saudi & Company 6 & 7 & 2 \\
$\mathbf{1 3}$ & 46 & Bachelor & Non-Saudi & Company 6 & 12 & 4 \\
$\mathbf{1 4}$ & 41 & Bachelor & Non-Saudi & Company 7 & 10 & 2 \\
\hline
\end{tabular}

\subsection{Project Milestones}

In this section, the project managers were asked questions on project milestones to cover the following elements:

1. Definition of project milestone

2. Difference between milestones and deliverables

\subsubsection{Definition of Project Milestone}

This paper provides an applied definition of project milestone which must come from project team rather than from scholars. The participants were asked the following question: What is a project milestone? According to the answers given by respondents, the previous question aims to obtain an understanding of project milestone. The following responses demonstrate how project managers can define the concept of milestone in project management. Theses answers can be classified into three groups.

Group one of project managers has almost the same view about the concept of project milestone by mention of 
the similar keywords. This group represents about $50 \%$ of the interview sample. The main used keywords to define milestone in project management are: end, phase, stage and task according to the below answers:

Table 2. Definitions of project milestone for group 1

\begin{tabular}{lll}
\hline Question & What is a project milestone? & \\
\hline PM \# & Answers & keywords \\
03 & "I think it [project milestone] is the end of a project phase" & End + Phase \\
04 & "Project milestone is the end of a project stage" & End + Stage \\
01 & "A milestone can be created to represent the end of phase in project" & End + Phase \\
12 & "My definition is that it [project milestone] is the end of project task" & End + Task \\
14 & "I think milestone is the end of completion of project phase" & End + Phase \\
09 & "a milestone is typically scheduled to occur at the end of a project stage" & End + Stage \\
06 & "I think every end of project task represent a project milestone" & End + Task \\
\hline
\end{tabular}

Group two of project managers (35.7\% of the sample) give a definition that comes from the definition of milestone in the Project Management Body of Knowledge (PMBOK). For this group, the main used keywords to describe milestone are: zero duration, activity and task according to the below answers:

Table 3. Definitions of project milestone for group 2

\begin{tabular}{lll}
\hline Question & What is a project milestone? & \\
\hline $\mathrm{PM} \#$ & Answers & keywords \\
07 & "I think project milestone is a zero duration task" & Zero duration + Task \\
02 & "According to PMI, milestones are zero duration activities in project" & Zero duration + Activity \\
13 & "A milestone can be defined as zero duration tasks" & Zero duration + Task \\
08 & "......so it [project milestone] is a zero duration task in project" & Zero duration + Task \\
10 & "as I learnt from PMBOK, an activity of zero duration is called milestone" & Zero duration + Activity \\
\hline
\end{tabular}

Group three of project managers (14.3\% of the sample) thinks that project milestone links with the following main keywords: progress and achievement as shown in Table 4:

Table 4. Definitions of project milestone for group 3

\begin{tabular}{lll}
\hline Question & What is a project milestone? & keywords \\
\hline PM \# & Answers & Achievement \\
05 & "I think project milestone is the achievement of a significant task in project" & Progress \\
11 & "In my opinion, a milestone can be defined as a progress marker in project schedule" \\
\hline
\end{tabular}

Regarding the above tables, there is no conflict in these practical definitions. Common project management words are used to define a project milestone. In this section, project managers give typical definitions which means they do not have any ambiguity about the concept of milestone. The next section shows the difference between milestones and deliverables in project management.

\subsubsection{Difference between Milestones and Deliverables in Project Management}

In a practical project, it is critical to investigate the difference between milestones and deliverables in the context of project management since them overlapping during project life cycle. The following interview question for the project managers was: What is the difference between milestones and deliverables?

The responses were analyzed to explore how milestones can be different from deliverables as shown in Table 5. 
Table 5. Difference between milestones and deliverables

\begin{tabular}{lll}
\hline No & Deliverable & Milestone \\
\hline 1 & Measurable product & Measurable progress \\
2 & Tangible product & Tangible event \\
3 & Outcome & Scheduled event \\
4 & Result & Specific point \\
5 & Output & Achievement \\
6 & Verifiable product & Practical step \\
\hline
\end{tabular}

According to Table 5, there is difference between milestones and deliverables in terms of both content and importance. Deliverables can be measurable, tangible, and verifiable as in the form of product, outcome, result, and output. On other hand, milestones can be measurable, tangible, scheduled, specific, and practical as in the form of progress, event, point, achievement and step. The following section shows the impact of project milestone on decision-making.

\subsection{Decision Making}

In this section, the project managers were asked questions on decision making to cover the structure of the interviews as follows:

1. Definition of decision

2. Decision making process

3. Impact of project milestone on decision-making

\subsubsection{The Impact of Project Milestone on Decision-Making}

According to the previous section, a milestone is a key and a marker event in a project schedule. The next interview question for the participants was: What is the effect of milestone on decision-making?

The above question aims to perceive the influence of milestone on decision-making during project life cycle. Regarding this question, the responses of project managers concentrate on the following points: 1) problem, 2) data, and 3) solution. The answers can be classified into three groups.

The above points are related in someway to milestone and decision-making. The following answers in Table 6 indicate how milestones can affect decision-making in terms of problem for group 1.

Table 6. Impact of Milestone on Decision-Making for Group 1

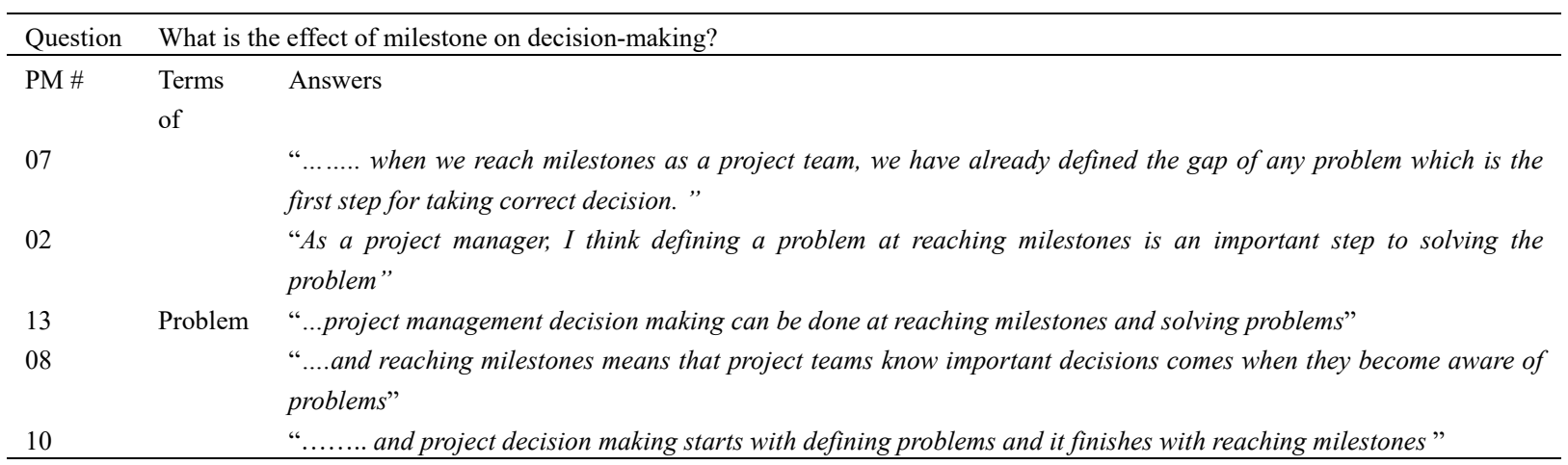

The following answers in Table 7 display how milestones can affect decision-making in terms of data for group 2 . 
Table 7. Impact of Milestone on Decision-Making for Group 2

\begin{tabular}{|c|c|c|}
\hline Question & \multicolumn{2}{|c|}{ What is the effect of milestone on decision-making? } \\
\hline PM \# & Terms of & Answers \\
\hline 07 & & "...every milestone phase includes data collection and data analysis which can help to take a decision in a project" \\
\hline 02 & & "...once a milestone is met, data analysis is important before taking a decision" \\
\hline 13 & Data & “...based on verified data, decisions are taken after milestones are achieved " \\
\hline 08 & & “...when milestones are completed, data collection and analysis process is necessary to take right decisions" \\
\hline
\end{tabular}

The following answers in Table 8 show how milestones can affect decision-making in terms of solution for group 3 .

Table 8. Impact of Milestone on Decision-Making for Group 3

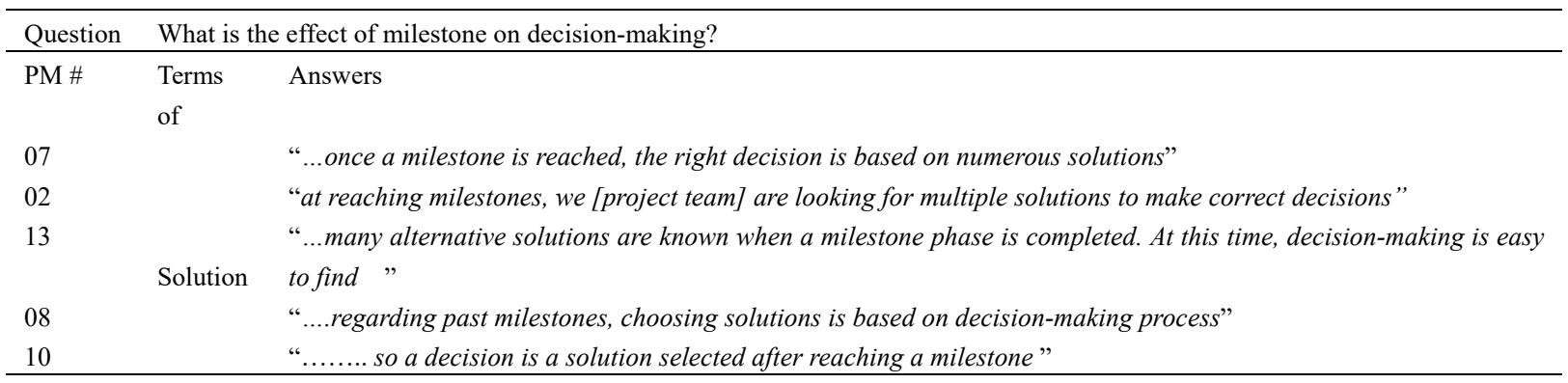

Table 6, 7, and 8 show that the impact of milestone on decision-making is real during project life. The factors of defining problems, collecting and analyzing data, and selecting solutions can play a role in making a decision in a project. The next section introduces the discussion.

\section{Discussion}

In this section, the main findings are summarized and introduced according to the research questions. The research questions of this paper were:

1) What is the importance of milestones in project management?

2) Is there a relationship between milestones and decision-making through project life cycle?

The first question aims to define the milestone by the project managers in their practical working life. The results for this question show that defining milestone is not complex although milestones are a marker of a project progress. The reason of that is, because PMI plays a role in raising awareness of project management knowledge and terminology. Every participant has their own definition of milestone. According to findings, milestones in a project are often related to end phase or task, zero duration, and progress. Also, this paper finds that deliverables are actual product while milestones are significant progress in a project. However, each milestone should be connected to deliverable.

The second question studies the relationship between milestones and decision-making through project life. The main purpose is also to identify the impact of milestone on decision-making. This paper is the first effort to empirically study the influence of milestone on decision-making in a project. Based on the answers given by the project managers in Table 6.7.8, reaching milestones means for project managers that:

- $\quad$ Problems are often defined in project environments.

- Data are collected and analysed at the project team level.

- $\quad$ Alternative solutions are selected.

Project managers in this study think that once milestones are reached, some considerations may be relevant to project management process as shown in Figure 4. 


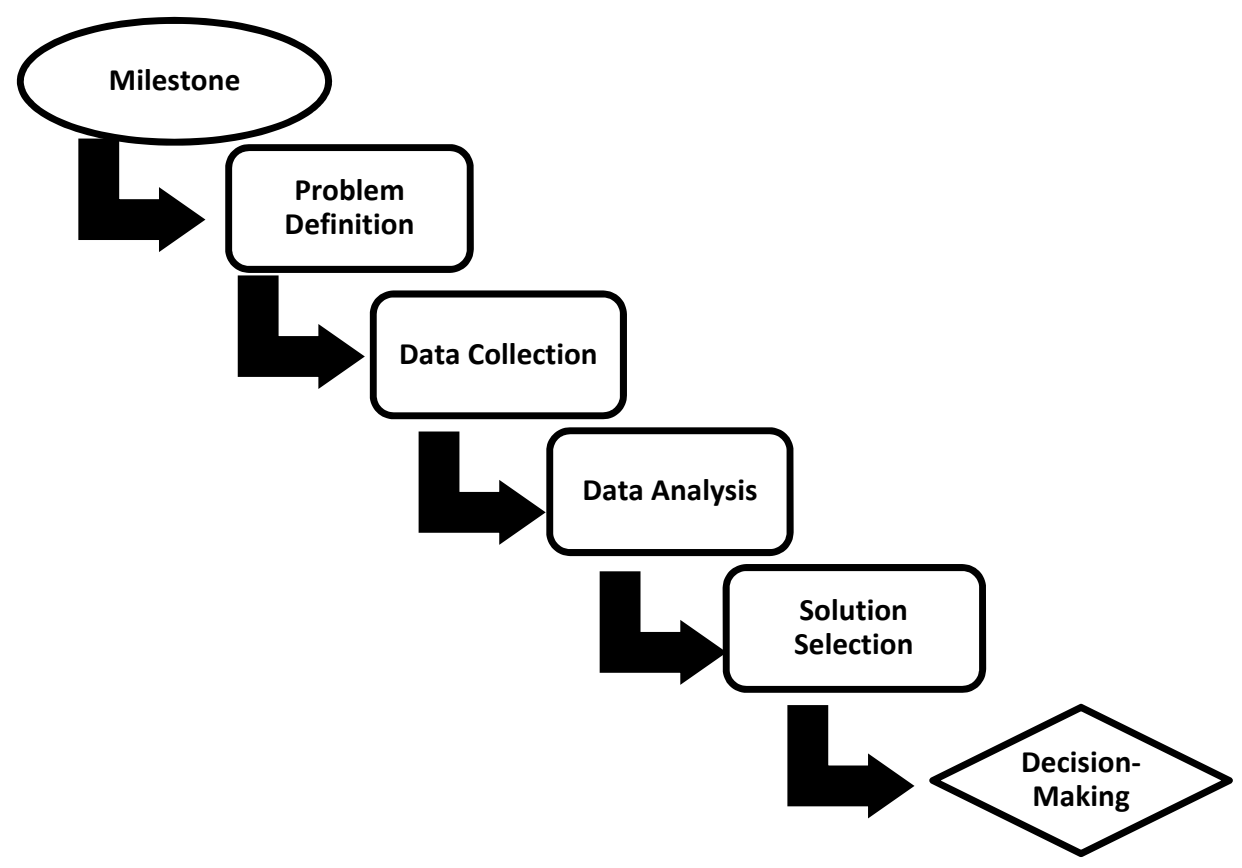

Figure 4. Relationship between milestones and decision-making

As seen in Figure 4, decision-making is a result of specific processes in project context. The impact of milestone on decision-making is based on the following processes:

- $\quad$ Problem Definition

- Data Collection

- Data Analysis

- Solution Selection

\section{Conclusions}

This study is a first attempt to add a contribution and knowledge to the literature on project milestone in Saudi Arabia. It aims to define how milestone affects decision-making. End phase, task, zero duration, and progress are elements of project milestone. This paper also finds there is difference between deliverables and milestones. The main finding at reaching milestone in project life is that decision-making depends on defining problem, collecting data, analyzing data, and selecting solution. More research about the relationship between milestones and decision-making will be necessary to verify these findings. Although the sample is small, it introduces valuable information about a project milestone and the impact on decision-making in the context of Saudi Arabia.

\section{References}

Ahtee, T., \& Poranen, T. (2007). Teaching software projects in universities at Tampere. Proceedings of INSPIRE XII: Improving Quality in Computer Education, 87-101.

Art Gowan, J., Mathieu, R. G., \& Hey, M. B. (2006). Earned value management in a data warehouse project. Information management \& computer security, 14(1), 37-50. https://doi.org/10.1108/09685220610648364

Baker, M. J., \& Abou-Ismail, F. (1993). Organizational buying behaviour in the Gulf. International Marketing Review, 10(1), 42-60. https://doi.org/10.1108/02651339310051614

Barczak, G., \& Wilemon, D. (2001). Factors influencing product development team satisfaction. European Journal of Innovation Management, 4(1), 32-36. https://doi.org/10.1108/14601060110365556

Basu, A. (2003). CPM scheduling in construction: A case study. AACE International Transactions, PS41. 
Bergner, K., \& Friedrich, J. (2010). Using project procedure diagrams for milestone planning. In International Conference on Software Process (pp. 88-99). Springer Berlin Heidelberg. https://doi.org/10.1007/978-3-642-14347-2_9

Boyatzis, R. E. (1998). Transforming qualitative information: Thematic analysis and code development. Sage.

Braun, V., \& Clarke, V. (2006). Using thematic analysis in psychology. Qualitative Research in Psychology, 3, 77-101. https://doi.org/10.1191/1478088706qp063oa

Chen, M., Yan, S., Wang, S. S., \& Liu, C. L. (2015). A generalized network flow model for the multi-mode resource-constrained project scheduling problem with discounted cash flows. Engineering Optimization, 47(2), 165-183. https://doi.org/10.1080/0305215X.2013.875167

Colenso, K. (2000). Creating the work breakdown structure. Artemis Management Systems.

Daymon, C. \& Holloway, I. (2002). Qualitative Research Methods in Public Relations and Marketing Communication. London: Routledge.

Doktor, R. H., \& Hamilton, W. F. (1973). Cognitive style and the acceptance of management science recommendations. Management Science, 19, 884-894. https://doi.org/10.1287/mnsc.19.8.884

Douglas III, E. E. (2004). Project Planning-Then Scheduling. AACE International Transactions, 71.

Ferreira, M. E., \& Tereso, A. P. (2014). Software Tools for Project Management-Focus on Collaborative Management. In New Perspectives in Information Systems and Technologies, Volume 2 (pp. 73-84). Springer International Publishing. https://doi.org/10.1007/978-3-319-05948-8_8

Gutfeld, T., Jessen, U., Wenzel, S., Laroque, C., \& Weber, J. (2014). A technical concept for plant engineering by simulation-based and logistic-integrated project management. In Proceedings of the Winter Simulation Conference (pp. 3423-3434). IEEE. https://doi.org/10.1109/WSC.2014.7020175

Halloran, L. (2010). Clinical study project plans. J Clin Res Best Pract, 6, 1-6.

Harren, V.A. (1979). A model of career decision- making for college students. Journal of Vocational Behaviour, 14, 119-133. https://doi.org/10.1016/0001-8791(79)90065-4

Helge Becker, K., \& Haunschild, A. (2003). The impact of boundaryless careers on organizational decision making: an analysis from the perspective of Luhmann's theory of social systems. International Journal of Human Resource Management, 14(5), 713-727. https://doi.org/10.1080/0958519032000080767

Hietala, M. (2009). Quality of project schedules in industrial projects. Helsinki University of Technology.

Hitt, M., Miller, C., \& Colella, A. (2006). Organizational Behavior: A Strategic Approach. Hoboken. Wiley.

Hormozi, A. M., \& Dube, L. F. (1999). Establishing project control: Schedule, cost, and quality. SAM Advanced Management Journal, 64(4), 32.

Huber, G. P., Sutcliffe, K. M., Miller, C. C., \& Glick, W. H. (1993). Understanding and predicting organizational change. Organizational change and redesign: Ideas and insights for improving performance, 215, 265.

Hwang, C. L., \& Masud, A. S. M. (2012). Multiple objective decision making-methods and applications: a state-of-the-art survey (Vol. 164). Springer Science \& Business Media.

Kampe, M. (2012). Characteristics of Good Milestones. Retrieved November 25, 2016, from http://www.cs.pomona.edu/classes/cs181f/supp/smart.html

Kingsbury, D. (1994). USAID Evaluation Special Study No. 73 PN-AAX-275.

Klimek, M., \& Łebkowski, P. (2013). Robustness of schedules for project scheduling problem with cash flow optimisation. Bulletin of the Polish Academy of Sciences: Technical Sciences, 61(4), 1005-1015. https://doi.org/10.2478/bpasts-2013-0108

Laporte, C. Y., Nabil, B., \& Mikel, D. (2012). Measuring the Cost of Software Quality of a Large Software Project at Bombardier Transportation: A Case Study. Software Qual. Manage, 14(3), 14-31.

Magalhães-Mendes, J. (2011). A two-level genetic algorithm for the multi-mode resource-constrained project scheduling problem.

Malladi, S., Dominic, P. D. D., \& Kamil, A. (2011). Lean principles in IT services: a case study on implementation and best practices. International Journal of Business Information Systems, 8(3), 247-268. https://doi.org/10.1504/IJBIS.2011.042408 
Marshall, M. N. (2014). Bridging the ivory towers and the swampy lowlands; increasing the impact of health services research on quality improvement. International journal for quality in health care, 26(1), 1-5. https://doi.org/10.1093/intqhe/mzt076

Mason, J. (2002). Qualitative Researching. London: Sage.

Miles, M. B., \& Huberman, A. M. (1994). Qualitative data analysis: A sourcebook. Beverly Hills: Sage Publications.

Moch, M. K., \& Morse, E. V. (1977). Size, centralization and organizational adoption of innovations. American sociological review, 716-725. https://doi.org/10.2307/2094861

Petrick, I. J., \& Susman, G. (1997). Decision-making strategies in product development teams. In Innovation in Technology Management-The Key to Global Leadership. PICMET'97: Portland International Conference on Management and Technology (p. 482). IEEE. https://doi.org/10.1109/PICMET.1997.653475

Project Management Institute. (2008). A Guide to the Project Management Body of Knowledge (PMBOK® Guide). 3rd ed. USA. https://doi.org/10.1007/s11518-006-0151-5

Rosenfelt, T. L. (2000). Project Management for the Modification of Multiple Major Manufacturing Systems in an Operating Factory (No. 2000-01-3030). SAE Technical Paper. https://doi.org/10.4271/2000-01-3030

Saaty, T. L. (2004). Decision making - the analytic hierarchy and network processes (AHP/ANP). Journal of systems science and systems engineering, 13(1), 1-35.

Schifalacqua, M., Costello, C., \& Denman, W. (2009). Roadmap for planned change, part 1: change leadership and project management. Nurse Leader, 7(2), 26-52. https://doi.org/10.1016/j.mnl.2009.01.003

Schwarcz, S. L. (2015). Excessive Corporate Risk-Taking and the Decline of Personal Blame. Emory Law Journal, 65(2).

Scott, S.G. \& Bruce, R.A. (1995). Decision-making style: The Development \& Assessment of a new measure. Educational \& Psychological Measurement. https://doi.org/10.1177/0013164495055005017

Sobel, R. S., \& Leeson, P. T. (2006). Government's response to Hurricane Katrina: A public choice analysis. Public Choice, 127(1-2), 55-73. https://doi.org/10.1007/s11127-006-7730-3

Soja, P., Themistocleous, M., \& Cunha, P. R. (2011). Playing Catch up: How Different Is Large Scale Enterprise Systems Implementation in Transition Countries and Organizations? In System Sciences (HICSS), 2011 44th Hawaii International Conference on (pp. 1-10). IEEE.

Tam, P. W. M., \& Dissanayake, P. B. G. (1998). Construction project scheduling by ranked positional weight method. Canadian Journal of Civil Engineering, 25(3), 424-436. https://doi.org/10.1139/197-100

Tausworthe, R. C. (1980). The work breakdown structure in software project management. Journal of Systems and Software, 1, 181-186. https://doi.org/10.1016/0164-1212(79)90018-9

Thirumalai, C., \& Senthilkumar, M. (2017). An Assessment Framework of Intuitionistic Fuzzy Network for C2B Decision Making. Electronics and Communication Systems (ICECS). https://doi.org/10.1109/ECS.2017.8067861

Vagstad, S. (2000). Centralized vs. decentralized procurement: Does dispersed information call for decentralized decision-making?. International Journal of Industrial Organization, 18(6), 949-963. https://doi.org/10.1016/S0167-7187(98)00044-7

Vanhoucke, M. (2011). On the dynamic use of project performance and schedule risk information during projecttracking. Omega, 39(4), 416-426. https://doi.org/10.1016/j.omega.2010.09.006

Vermeulen, P. A. M., \& Curseuurseu, P. L. (Eds.). (2010). Entrepreneurial strategic decision-making: A cognitive perspective. Edward Elgar Publishing.

Wallin, C., Larsson, S., Ekdahl, F., \& Crnkovic, I. (2002). Combining models for business decisions and software development. In Euromicro Conference. Proceedings. 28th (pp. 266-271). IEEE. https://doi.org/10.1109/EURMIC.2002.1046171

Wigal, G. S. (1990). Interference with a Contractor's Early Completion of a Construction Project. Constr. Law, 10, 17. 


\section{Copyrights}

Copyright for this article is retained by the author(s), with first publication rights granted to the journal.

This is an open-access article distributed under the terms and conditions of the Creative Commons Attribution license (http://creativecommons.org/licenses/by/4.0/). 